The Process of Forming a Mobile Media Habit: Results of a Longitudinal Study in a Real-World Setting

Anna Schnauber-Stockmann \& Teresa K. Naab

The final version of this article is available here:

Schnauber-Stockmann, A. \& Naab, T. K. (2019). The process of forming a mobile media habit: results of a longitudinal study in a real-world setting. Media Psychology, 22(5), 714-742.doi:10.1080/15213269.2018.1513850

Dr. Anna Schnauber-Stockmann, Department of Communication, University of Mainz, Jakob-Welder-Weg 12, 55099 Mainz, Germany. E-Mail: anna.schnauber-stockmann@unimainz.de, phone: +4961313925637

Dr. Teresa K. Naab, Department of Media, Knowledge and Communication, University of Augsburg, Universitaetsstrasse 10, 86159 Augsburg, Germany. E-Mail: teresa.naab@phil.uni-augsburg.de, phone: +498215985933

Correspondence concerning this article should be addressed to Dr. Anna SchnauberStockmann, Department of Communication, University of Mainz, Jakob-Welder-Weg 12, 55099 Mainz, Germany. E-Mail: anna.schnauber-stockmann@uni-mainz.de 


\begin{abstract}
Media habits are central constructs in audience research. Yet, little is known about the formation of (media) habits. Based on theoretical elaboration and the results of a longitudinal study on the formation of a mobile media application habit - specifically the UEFA Euro App 2016 - in a real-world setting, the present paper develops a comprehensive framework of media habit formation. The framework focuses on the core process of habit formation: Habits form with (regular) repetition of a behavior in a specific context which is perceived as rewarding. Yet, the findings of the study show that regularity in behavior performance and stable external circumstances are less crucial for the formation of a mobile media habit. Instead, gateway behaviors are proposed as relevant context features for the formation of mobile media habits.
\end{abstract}

Keywords: habit formation, media habits, mobile media, longitudinal survey, multilevel analysis, smartphone application 


\section{The Process of Forming a Mobile Media Habit: Results of a Longitudinal Study in a Real-World Setting}

Imagine discovering an interesting app that provides recent information about your favorite sports. Probably, once discovered you would open the app a couple of times to check whether it is worth using. If you like it, you would probably use it repeatedly to keep up to date with developments in the sports world. After a while, selecting the app may turn into a habit.

Habit definitions vary to some extent, yet many researchers agree on the basic notion that a habit is an automatically initiated behavioral response stored as a mental representation (LaRose, 2010; Naab \& Schnauber, 2016; Verplanken \& Aarts, 1999; Wood \& Rünger, 2016). The focus of habit research mainly rests on measurement issues related to habit strength (e.g., Gardner, de Bruijn, \& Lally, 2011; Naab \& Schnauber, 2016; Verplanken \& Orbell, 2003), on examining the influence of habit strength on behavior performance (e.g., Danner, Aarts, \& de Vries, 2008; LaRose \& Eastin, 2004; LaRose, Lin, \& Eastin, 2003; Ouellette \& Wood, 1998), and on further constructs of the reception process (e.g., Bayer, Dal Cin, Campbell, \& Panek, 2016). While most publications include notions of habit formation, detailed theoretical conceptions and empirical examinations of how people form habits are rare (exceptions are mainly from health research, e.g., Armitage, 2005; Lally, Chipperfield, \& Wardle, 2008; Lally \& Gardner, 2013; Lally, van Jaarsveld, Potts, \& Wardle, 2010; Marcus et al., 2000). Apart from LaRose's (2010) theoretical considerations on the formation of media habits, communication research has rarely touched upon this issue (for exceptions see Kim, 2014; Tokunaga, 2013). However, information systems researchers are interested in the formation process of habits (Limayem, Hirt, \& Cheung, 2007) and include habit formation as an explanatory factor in their models of technology adoption and use (e.g., Kim, 2012; Kim, 
Malhotra, \& Narasimhan, 2005; Limayem \& Hirt, 2003; Murray \& Häubl, 2007; Venkatesh, Thong, \& Xu, 2012).

It is surprising that the formation of media habits has received little attention so far given the importance attributed to habits: Communication research has shown the relevance of media habits (e.g., Bayer \& Campbell, 2012; Peters, 2007; Schnauber \& Wolf, 2016), media users perceive their media selection as habitual (Cooper \& Tang, 2009), and media practitioners work on establishing media habits (Eastman \& Ferguson, 2002). This points to the necessity of understanding the dynamics of how media users turn into habitual media users. The present paper aims at contributing to this research topic by focusing on the core process of habit formation, that is the interplay of repetition, regularity, context stability, and perceived rewards of a behavior. It hereby gives specific consideration to mobile media habits (e.g., Bayer \& Campbell, 2012; Bayer et al., 2016; Peters, 2007; Schnauber \& Wolf, 2016) and investigates the formation of a mobile media application habit.

We present the results of a longitudinal field study on the formation of a smartphone application habit that contributes to a better understanding of the particularities of mobile media habits and their consequences for the process of habit formation. The study is among the very few that have collected daily observations of participants over an extended period of one month to draw a detailed picture of the process of habit formation (Wood \& Neal, 2016). In part, the study can serve as a replication of Lally et al.'s (2010) outstanding empirical work on the formation of health-related habits and thus provides empirical evidence on the generalizability of their results to the behavioral domain of mobile media application use. In addition to this replication, the present study extends existing findings in several ways: We test the influence of perceived rewards and context stability for mobile media application habit formation. The results derived from this innovative aspect set ground for introducing the idea of 'gateway behaviors' to habit research. Gateway behaviors will be outlined as 
context features relevant for habit formation. Moreover, we conduct a multilevel analysis to model habit formation adequately given the nested data structure. Based on the theoretical considerations and empirical results of our study, this paper is the first to propose a comprehensive framework of interrelated determinants of media habit formation.

\section{(Mobile) Media Habits}

Two characteristics in particular make media use an interesting case for studying habit formation: First, media use may serve a variety of goals and provide a multitude of gratifications (e.g., entertainment, information, pass time). Although this also holds for other habits (e.g., transportation habits; Klöckner, Matthies, \& Hunecke, 2003), many behaviors often referred to as being habitual in everyday life serve specific purposes (e.g., seat belt use; Mittal, 1988). In contrast, media habits can be general in nature, serving varying needs efficiently (for an elaboration on specific vs. general media habits see Naab \& Schnauber, 2016). Second, media content provides novel characteristics in each use episode, distinguishing media habits from many other habits, for example putting on a seat belt, which contain similar procedures and 'content' each time. This has consequences for perceived rewards, that is payoffs of the behavior. Rewards depend on the changing media content and might therefore be intermittent. As we will elaborate below, intermittent rewards can be beneficial for habit formation (Wood \& Neal, 2016).

With the spread of mobile technology, many media behaviors can be performed ubiquitously. This brings new challenges for habit theory and research: A central assumption is that the formation of habits depends on stable contexts (e.g., Ji \& Wood, 2007). However, not all behaviors which are perceived to be habits take place in stable external circumstances. Focusing on mobile media habits thus seems valuable for a better understanding of the formation of (mobile media) habits in varying circumstances. 
The characteristics of media behaviors set boundary conditions to the core process of habit formation, that is the interplay of repetition, regularity, perceived rewards, and context features for habit formation (see 'The Core Process of Habit Formation'). When interested in this core process, it seems advisable to keep boundary conditions constant. We therefore researched the formation of a specific mobile media habit, namely the smartphone application of the Union of European Football Associations for the European soccer championship 2016 (UEFA Euro App 2016). The app contained up-to-date information on the European soccer championship. Like many news apps, it provided the same content and update intervals for all users. In that, it differed from social media apps, messenger apps, and gaming apps whose personalized content depends on the users' individual usage and their social networks' behavior. Unlike most news or sports apps, the UEFA Euro App 2016 covered one topic, namely the European soccer championship. The schedule of the tournament set fixed 'events' receiving special attention. However, many other aspects related to the tournament and the different teams were covered as well, therefore the app provided new content on a daily basis in irregular intervals like more general news apps.

When investigating habit formation, tracking the formation process right from the beginning of a newly adopted behavior is necessary to examine habit development at an initial stage and later stages. The UEFA Euro App 2016 allowed for such research design. The app was launched specifically for the European soccer championship and the field period of the study started right before the first game (June, $10^{\text {th }}$ to July, $10^{\text {th }} 2016$ ).

Researching this particular mobile media application will affect the theoretical focus of the paper. When elaborating on factors determining habit formation in the next section, we will also outline how the particularities of the UEFA Euro App 2016 sets boundary conditions to the core process of habit formation. 


\section{The Core Process of Habit Formation}

Several factors influencing habit formation are discussed in the literature. The present paper aims at integrating these factors into a coherent theoretical framework (see 'A Comprehensive Framework of Media Habit Formation'). In the following, we describe the core process of habit formation: (regular) repetition of a behavior in a specific context which is perceived as rewarding. We hereby elaborate on the different determinants and their interrelations in detail and point out specifics of mobile media habits.

\section{Repetition and Regularity}

The central determinant of habit formation is repetition of a behavior. Repetition of a behavior is a necessary precondition to forming a mental representation of the habitual response connecting the behavior to its circumstances and consequences. The mental representation of the behavior may be understood as a form of "chunking' the behavior together into a unit" (Smith \& Graybiel, 2016, p. 34; see also Gardner, Phillips, \& Judah, 2016). Action steps are merged into a higher-order behavior (Gardner et al., 2016). For example, the use of the UEFA Euro App 2016 may consist of the steps 'pushing the app button', 'reading the first headline', then 'skip to game results'.

Once a habit forms, formerly intentional behavior becomes automatic, that is initiated with little awareness, attention, and controllability (Bargh, 1994). Thus, habit formation is based on operant learning and repeated practice of a behavior, which sets habits apart from other forms of automaticity, for example reflexes. Therefore, researchers agree that habits form through repetition (e.g., Carden \& Wood, 2018; Redish, Jensen, \& Johnson, 2008; Verplanken \& Aarts, 1999).

Empirical evidence on the number of repetitions necessary for habit formation is scarce, however. Several information systems studies with a small number of panel waves indicate that habit strength increases with the number of repetitions, yet these studies do not 
aim at tracing the process of habit formation (e.g., Limayem \& Hirt, 2003; Venkatesh et al., 2012). In an experimental setting, Murray and Häubl (2007) find support that nine repetitions of using an online interface increases habitual choice of this interface compared to only one usage experience. The participants of the study by Lally et al. (2008) experienced automaticity in their daily weight loss behaviors after three months. Armitage (2005) found that the influence of past physical exercise on future performance of this behavior decreases after five weeks of weekly repetition suggesting an increase in habituation.

The relationship between repetition and habit strength is most probably not linear: After a certain number of repetitions, habit strength growth decelerates-further repetitions lead to smaller increases until the process of habit formation ceases and habit strength reaches its (individual) maximum (Hull, 1943). Lally et al. (2010) provide one of the rare examinations of the process of habit formation in a real-world setting. They researched health-related behaviors of eating, drinking, and exercising and had participants perform the behavior repeatedly over three months. Their results show that habit strength increases with repetition and that this relationship follows an asymptotic curve. "Early repetitions result in larger increases in automaticity than those later in the habit formation process, and there is a point at which the behavior cannot become more automatic even with further repetition" (p. 1007). We therefore hypothesize:

H1a: Mobile media habit strength increases with the number of repetitions of the behavior.

H1b: The relationship between the number of repetitions and mobile media habit strength is not linear, but decelerates with the number of repetitions. 
Hereby, Lally et al. (2010) found differences between participants regarding how long it took until they performed their health-related behavior habitually. This may be due to boundary conditions such as personality characteristics. For instance, individuals differ in their trait self-control (Tangney, Baumeister, \& Boone, 2004; Wood \& Rünger, 2016) and their tendency to embrace repetitive and reliable structures in everyday life (Thompson, Naccarato, Parker, \& Moskowitz, 2001). This leads to differences in their susceptibility to automatic behavioral control. Furthermore, media behaviors differ in the complexity of using the respective devices and processing the provided content. More complex behaviors that require high levels of flexibility in performance will less likely become habitual or take longer to habitualize (Lally et al., 2010; Redish et al., 2008; Verplanken, 2006).

Related to the influence of repetition on habit formation is the influence of regularity. Regularity indicates that the repetition of a behavior follows a temporal pattern, for example each day, week, or year, which is not interrupted by omissions. The temporal availability and structure of media content influences the potential repetition intervals and regularity of media behaviors. Some media content is provided on a predetermined schedule at fixed times—on a yearly (e.g., the broadcasting of the Super Bowl), weekly (e.g., new episodes of a show or podcast releases), or daily basis (e.g., television news). Other content is updated at irregular times (e.g., social media, news applications). We keep this boundary condition constant when focusing on the UEFA Euro App 2016. The app was updated several times a day during the period of the European soccer championship. Thus, users could check the app daily. This allows for tracking habit formation on a daily basis and the expectation of increases in habit strength within a reasonably long field period (one month).

Empirical results on the influence of regularity are scarce. Armitage (2005) shows that future performance of the weekly physical exercise is less likely after omissions of one week. In particular, omissions within the first weeks hinder future performance. Lally et al. (2010) 
present a more fine-grained analysis of daily health behaviors. Contrary to the findings of Armitage (2005), they conclude: “[...] missing a day resulted in a non-significantly lower SRHI score [self-report habit index; the authors] the following day, but there were no longerterm costs associated with a single omission" (p. 1006; see also Lally, Wardle, \& Gardner, 2011). This suggests that habits can form despite omissions. Therefore, we ask:

RQ1: Do omissions in behavior performance influence mobile media habit formation?

\section{Context Stability}

Repeated execution of a behavior can be understood as the basis for habit formation. However, it is not mere repetition that is decisive, but the setting in which the behavior is repeated is important, too: A necessary precondition for habit formation is the co-occurrence of the behavior with stable context features (e.g., Gardner, 2015; Lally et al., 2010; Ouellette \& Wood, 1998; Wood \& Neal, 2016). The behavior has to be performed not only repeatedly, but also in stable contexts. The formation of a mental representation of the habitual response depends on the reliably repeated co-occurrence necessary for encoding in procedural memory (McClelland, McNaughton \& O'Reilly, 1995). This pattern of co-occurrence between context features and a behavior may happen intentionally or unintentionally. Once a habit is formed, further perception of the respective context triggers the associated behavioral response without deliberate decision-making and little control over the behavior (Redish et al., 2008; Wood \& Neal, 2007).

Habit researchers mostly refer to external circumstances as relevant context features co-occurring with the behavior to form a mental representation of the habitual response. Examples are time (of the day, week, or year), place (e.g., the living room), social surroundings (e.g., when in the company of specific people or being alone), and prior or 
parallel activities (e.g., after or while having lunch; Ji \& Wood, 2007). Some researchers also include internal factors like mood and goals (for a discussion see e.g., Naab \& Schnauber, 2016; Wood \& Neal, 2007). Furthermore, a myriad of other internal and external factorssolely or in combination-may function as context features (Gardner, 2015; see McDaniel \& Einstein, 1993; 2000 on the effectiveness of different context cues to elicit automatic responses).

Based on this notion of reliable co-occurrence of context features and behavior, intervention programs for habit formation recommend deliberately performing the behavior in specific (mostly external) situational circumstances. This is also called forming and performing an implementation intention (e.g., 'During vacation, I will go for a run each day after breakfast' instead of 'I will go for a run each day during vacation'; Gollwitzer, 1999). Results show that implementation intentions connecting a behavior to context features are more likely to be acted upon regularly (for an overview see e.g., Gollwitzer \& Sheeran, 2006). In consequence, the behavior will more likely form into a habit and need less intentional planning after repeating it in the specific context several times (Holland, Aarts, \& Langendam, 2006; Wood \& Neal, 2016). Thus, although in the initial stage the procedure explicitly focuses on intentional performance, over time the automatic character takes over because implementation intentions provide for reliable repetition in a stable context.

However, media habit researchers found evidence that existing media habits — unlike other habitual behavior — are not instigated in stable contexts as defined above (Kim, 2014; Naab \& Schnauber, 2016; Newell, 2003; Schnauber, 2017; Schnauber \& Wolf, 2016). They speculate that while context stability is relevant in habit formation, it is not once the habit is formed (LaRose, 2010; Naab \& Schnauber, 2016). Whether context stability is necessary for habit formation and interacts with repetition of the behavior has barely been put to an empirical test. This is especially the case with regard to the formation of mobile media 
application habits (for an exception see Kim, 2014). The ubiquitous availability of media devices allows for usage in determined circumstances, but does not afford them. We therefore aim at extending the research on mobile media habits by testing the following hypotheses.

H2a: Mobile media habit strength increases when the behavior is performed in a stable context.

H2b: Context stability moderates the relationship between mobile media habit strength and the number of repetitions: The positive relationship between the number of repetitions and mobile media habit strength gets stronger by performances in a stable context.

\section{Perceived Rewards}

Besides the repeated execution of the behavior in co-occurrence with stable context features, reinforcement of the behavior, mainly in the form of rewards, is discussed as a precondition of habit formation (Gardner, 2015; Smith \& Graybiel, 2016; Wood \& Neal, 2016). Rewards may come in the form of (monetary or other) incentives or payoffs of the behavior itself. Repeatedly rewarding experiences strengthen the formation of a mental representation of the habitual response by stamping the association between context features and behavior (for comprehensive overviews see Graybiel \& Smith, 2014; Wood \& Rünger, 2016). Once a habit is formed, individuals automatically give attentional priority to context features associated with the rewarded behavior and performance is triggered without intention (Anderson, 2016; Carden \& Wood, 2018). Repeatedly rewarding experiences associate the behavior with positive immediate outcome expectations which finally lead to stable, long-run outcome expectations (LaRose, 2010). Whether recurring rewarding experiences are relevant for habit maintenance, seems to depend on the stage of habit 
formation: Smith and Graybiel (2016) suggest that whereas habits at first are reward or outcome sensitive ('AO habits'), intensive execution of the behavior leads to reward or outcome insensitive - and therefore very stable - habits ('SR habits'). In the same vein, LaRose (2010) differentiates between a phase of habit acquisition (reward sensitive) and habit activation (reward insensitive). In any case, habits seem to lead to individuals noticing when a reward is received but not when the behavior fails to provide a reward. This leads to the notion that SR habits only decay very slowly after repeatedly devalued experiences (Smith \& Graybiel, 2016).

Laboratory research indicates that habit formation is fostered by rewards that do not always occur (Wood \& Neal, 2016). This intermittent reward structure as a payoff of the behavior is inherent to media use due to the ever-changing content provided. Media content may be more or less informative, entertaining, and so on in each media use episode. This also applies to the UEFA Euro App 2016. Due to its irregular updating intervals, opening the app may or may not provide new content and will be more or less informative in different use episodes. Surely, media behaviors also differ in their gratification potential for users: Whereas some individuals are interested in, for example, soccer, others are not. This might influence immediate and long-term outcome expectations that users associate with their use of a specific media behavior and thus influence habit formation (LaRose, 2010). Focusing on one particular media content, namely the UEFA Euro App 2016, ensures inter-individual variation in perceived rewards.

Results by LaRose and colleagues (LaRose \& Eastin, 2004; LaRose et al., 2003) support the general influence of expected outcomes of Internet usage on Internet habit strength. Limayem et al. (2007) show that the extent of satisfaction with the outcomes of technology use increases with repeated experience and leads to greater habit strength (see also Kim, 2012; Murray \& Häubl, 2007). Limayem and Hirt (2003) report exploratory 
evidence that providing incentives can strengthen habit formation at an initial stage of behavior adoption, while incentives seem to be less instrumental later on when perceived rewards, as direct payoffs of the behavior resulting in positive outcome expectations, are more influential (similarly for the long-term effect of monetary incentives, Mantzari et al., 2015). In the same vein, Wood \& Neal (2016) conclude that rewards in the form of payoffs of the behavior itself are especially successful in strengthening the formation of habits. We therefore aim to contribute to media habit research by testing the longitudinal influence of perceived payoffs of the behavior on habit formation.

H3a: Mobile media habit strength increases when the behavior itself is perceived as rewarding.

H3b: Perceived rewards moderate the relationship between mobile media habit strength and the number of repetitions: The positive relationship between the number of repetitions and mobile media habit strength gets stronger if the behavior is perceived as rewarding.

\section{Method}

\section{Participants and Procedure}

We conducted a longitudinal self-report study on the formation of a mobile media application habit over 30 days, complemented by an initial questionnaire. All participants used the German version of the UEFA Euro App 2016. Not letting participants choose a media behavior of their individual interest should lead to inter-individual variation in perceived rewards as payoffs of the behavior. This allows for testing the influence of rewards on habit formation. Furthermore, it served to keep many characteristics of media behaviors constant that might influence the core process of habit formation as boundary conditions. The app was permanently temporally and spatially available and provided the same non- 
personalized content updates for all participants at the same time. Of course, the choice of a specific app limits the generalizability of the results as the study did not test particular mediaspecific boundary conditions of habit formation. However, it seemed advisable to focus on the core process given the limited knowledge on habit formation in media research. The field period lasted one month, covering the whole European soccer championship from June, $10^{\text {th }}$ to July, $10^{\text {th }} 2016$. The app was compatible with the most common smartphone operating systems (i.e., Android and IOS) and was free of charge.

Fifty-three undergraduate students participated in the study. Thus, the sample was rather homogeneous, not covering for example different age and education groups. This limits the generalizability of the results as personality characteristics may influence habit formation. Still, a homogeneous sample keeps potential boundary conditions such as, for instance, smartphone skills constant. This is beneficial for the study's goal to identify the core process of habit formation. All participants were smartphone users. They were recruited by trained student assistants as part of a survey research course. Each student recruited at least two participants, one female and one male. Participants were instructed how to install the app on their smartphones and place it on the first screen or in a place where they would likely see the icon each time they switched on their smartphones.

Based on research on interventions to create habits (e.g., Holland et al., 2006), each participant formed an implementation intention on using the UEFA Euro App 2016 each day of the European soccer championship to keep up to date with the ongoing tournament: They chose one specific daily occasion that occurred once a day every day and fitted into their individual schedules, for example 'I use the app when getting up in the morning' or 'after lunch'. The chosen occasions were not related to the tournament of the European soccer championship. There were no instructions on whether participants could use the app more often during the day. 
Participants were asked to fill out a one-page paper-and-pencil questionnaire once a day as well as complete a short initial survey (see 'Measures'). Respondents did not receive monetary or other incentives for participation since incentives might interfere with the effect of perceived rewards as payoffs of app use. To ensure continued participation in the demanding study procedure, participants were supported by trained student assistants. The student assistants briefed participants intensively on the study's procedure and maintained contact during the field period. Communication between assistants and participants was not related to participants' repeated use of the app, but to continuously filling out the questionnaires. The assistants motivated participants to complete the study while they did not intrude on their use of the app. We cannot exclude the possibility that the social support influenced the habit formation process. Yet, it seems appropriate given the effortful longitudinal design.

Of the 53 initially recruited participants, 51 successfully completed the study and handed in all paper questionnaires. Seventy-one percent filled out all questionnaires; no participant skipped more than six questionnaires. Fifty-one percent were male, the mean age was $21.18(S D=2.06)$.

\section{Measures}

Repetition. Each day, participants reported whether they had used the app. From this information, we created the variable 'number of repetitions'. The variable indicated the number of days on which the participant had used the app prior to the respective day. For example, if a participant had used the app each day from study day one to day four, they received a '4' as value for the number of prior repetitions on day five. If this participant did not use the app on day five, the value for the number of repetitions on day six stayed at ' 4 '. If they used the app on day six, the value for day seven went up to ' 5 '. Additionally, participants specified for each day how many times they had used the app. If the app was 
used at least once on a day, participants answered further questions on context stability, perceived rewards, and habit strength.

Omissions in behavior performance (regularity). From the information on which days a participant had used the app, we further computed a variable indicating for each day how many consecutive days a participant had omitted using the app prior to the respective day. For example, if a participant had used the app each day at day five, they received a ' 0 '. If the participant did not use the app on day five, the value for day six was ' 1 '. Another omission on day six lead to a value of ' 2 ' on day seven. If the app was used on day seven, the value for day eight was ' 0 ', that is the count of omissions started anew every time the participant had used the app at least once.

Context stability. Participants indicated for each day of using the app whether they had used the app on the respective day (1) only during their individually selected daily occasion, (2) during their individually selected daily occasion, but also during other occasions, or (3) only during other occasions. For each day, the percentage of previous days the participant had used the app only or also during the selected occasion (i.e., values 1 and 2) was computed, representing context stability. For example, when a participant had used the app only or also during the selected occasion from day one to five, they showed a context stability of 100 percent on day six. If the participant had used the app only or also during the selected occasion on day one and two, but not on day three, four, and five, they showed a context stability of 40 percent on day six.

Perceived rewards. A single item measured whether the app use was perceived as rewarding by the participant ("Using the app today was rewarding", scale from 0 does not apply at all to 4 completely applies). For data analysis, we computed the percentage of previously rewarding experiences (scale points 3 and 4) for each day over all previous days the app was used at least once (comparable to the percentage count of 'context stability'). 
Habit strength. A four-item short version of the self-report habit index (SRHI, Verplanken \& Orbell, 2003) focusing on behavioral automaticity (Gardner, Abraham, Lally, \& de Bruijn, 2012; see also Lally et al., 2010) measured habit strength. The items were adapted to capture automatic initiation (Gardner et al., 2016), that is automaticity in opening the app: "Today, I opened the app... (1) automatically, (2) without having to consciously remember, (3) without thinking about it, (4) without realizing I'm doing it'. Participants rated these items on a scale from 0 does not apply at all to 4 completely applies. We created a sum scale of habit strength for each day the app was used ranging from 0 to 16 , showing good internal consistency (mean alpha coefficient across all study days $\alpha=.90$ ).

Socio-demographics and additional participant information. In the complementary questionnaire prior to the longitudinal study, participants' gender and age were assessed. Furthermore, respondents indicated how interested they were in the European soccer championship ( 0 not interested at all to 4 very interested; $M=2.75, S D=1.28$ ). Participants also stated whether they already knew the UEFA Euro App 2016 and had already used it. Nine participants (18\%) already knew the UEFA Euro App 2016 and three (6\%) had already used it. However, as the app did not contain a significant amount of content before the start of the European soccer championship, no extensive use was possible. ${ }^{1}$ Finally, smartphone habit strength was measured by an adapted version of the SRHI (Verplanken \& Orbell, 2003) focusing on automatic initiation for each participant and used as a control variable in the following analyses $\left(11\right.$ items,${ }^{2}$ measured on a scale from 0 does not apply at all to 4 completely applies, sum scale from 0 (lowest habit) to 44 (highest habit strength); $M=25.63, S D=7.65, \alpha=.87)$.

\footnotetext{
${ }^{1}$ Excluding these participants did not change the results; therefore, they are included in the presented analyses.

${ }^{2}$ The original SRHI contains an item measuring self-concept ('that's typically me'). Self-concept, however, is not an integral part of the habit concept and the respective item was excluded from the SRHI (Gardner, 2015; Lally et al., 2010).
} 


\section{Data Analysis}

To account for the nested data structure (i.e., repeated measures of the same individuals), we conducted multilevel analyses (MLA). MLA has major advantages over traditional approaches (Hox, 2010): It does not require balanced data and thus can handle that the number of observations differs between individuals (i.e., some participants did not use the app on each of the 30 days of the study or did not fill each daily questionnaire, producing missing observations for some days). MLA allows for modelling linear as well as non-linear trends, which is inevitable as we assume that habit strength grows with the number of repetitions whereby growth is stronger at the beginning and then decelerates (H1a and H1b). To obtain a good model fit for this trend over time, we included the linear term of the number of days on which the behavior was repeated until the current day of the study as well as its quadratic term to predict habit strength on each day of the study. Furthermore, MLA allows for testing of individual differences. As participants can be expected to vary in their habit formation (Lally et al., 2010, see 'Repetition and Regularity'), we tested for significant varying slopes between individuals (deviance difference test; Hox, 2010). MLA allows for adding time-varying as well as time-invariant variables potentially affecting the development of the dependent variable. To test $\mathrm{H} 2$ to $\mathrm{H} 3$ and answer RQ1, we included regularity in the form of the number of omissions (RQ1), context stability (H2a), and perceived rewards (H3a) on the situation level into the model. The interactions of the latter two with the days the behavior was repeated (linear and quadratic term) served to test the moderation hypotheses $\mathrm{H} 2 \mathrm{~b}$ and $\mathrm{H} 3 \mathrm{~b}$. Additionally, smartphone habit strength on the person level (grand mean centered) was included as a control variable. Aside from overall smartphone habit strength, further variables could be potentially relevant control variables. With regard to person level factors, prior experiences with similar apps (0 no vs. 1 yes) or general smartphone use for soccer information ( 1 never to 5 several times a day) in particular may influence the ease of 
habit formation. Furthermore, socio-demographics such as age and gender may have an impact on habit formation. However, when introduced in the MLAs none of these variables influenced habit formation. With regard to events in the tournament, whether the German team was playing or not on a specific day is another potentially relevant control variable as most study participants were in favor of the German team. When including in the MLAs whether a participant was a fan of the team (0 no vs. 1 yes) as well as whether the German team was playing (1) or not (0), we found no significant effects. In the same vein, the fortunes of the German team (1 Germany in the tournament vs. 0 Germany eliminated from the tournament) did not affect habit strength. To keep the models parsimonious, we refrained from including the aforementioned variables in our final analyses.

The following MLAs are based on 1162 measurements (level 1, i.e., daily observations of all participants over a period of 30 days) from 51 individuals (level 2). Although there are no strict conventions on adequate sample sizes on both levels, simulation studies indicate that with at least 50 level-2 units (in our case individuals, $N=51$ ), most parameters and their standard errors are estimated sufficiently accurately on both levels (Maas \& Hox, 2005; Snijders, 2005; for an overview see, Hox, 2010). This holds true even when few $(N=5)$ level-1 units (in our case daily observations) exist per level-2 unit. In the current study, no individual reported less than 12 daily observations $\left(N_{\text {average }}=23\right)$. The accuracy is relevant as biased standard errors lead to erroneous power estimations. Simulation studies on such estimates of statistical power to detect medium (fixed) effects (Cohen, 1988) point to adequate power given the current sample size (51 individuals with an average of 23 daily observations; Scherbaum \& Ferreter, 2009).

\section{Results}

On average, participants used the UEFA Euro App 2016 on 23 days during the 30 day period under investigation $(M=23.20, S D=5.24, \operatorname{Min}=12, \operatorname{Max}=30)$ and 41 times 
$(M=41.03, S D=24.43, \operatorname{Min}=16, \operatorname{Max}=170)$. Whether participants perceived app use as rewarding (across all days and participants: $M=2.01)$, varied inter- $(S D=0.81)$ as well as intra-individually $(S D=0.88)$. Whereas inter-individual variation was relevant for testing whether perceived rewards influence the habit formation of individuals, intra-individual variation in reward perception across days points to the intermittent reward structure of media use. Respondents started with an average habit strength of $1.02(S D=2.07, \operatorname{Min}=0$, Max $=9)$ and reached a habit strength of 3.73 on the last observation day of each participant $(S D=4.20, \operatorname{Min}=0, \operatorname{Max}=13)$. Compared to the theoretical maximum of 16, this indicated rather low overall habit strength across the sample (see 'Limitations'). However, importantly for hypotheses testing we found intra-individual variation in habit strength during the field period for most participants (43 individuals, 84\%). In turn, eight participants (16\%) did not show any habit formation. On average, habit strength of those participants whose habits got stronger from the first to the last day of the study increased by $5.03(S D=3.48, \operatorname{Min}=1$, Max = 13). Thus, the data allowed for testing the influence of the variables of interest.

In a first step, we modelled the relationship between repetition and habit strength. Table 1 summarizes the results. As expected, habit strength increased with the number of repetitions $(b=0.08 ; t=9.49 ; p<.001 ; \mathrm{H} 1$ a supported $)$. This increase was not linear, but decelerated, as indicated by the significantly better model fit when including the quadratic term and its significant negative regression weight $(b=-0.01 ; t=-2.09 ; p<.05 ; \mathrm{H} 1 \mathrm{~b}$ supported). The slope (significant random slope of the linear term: $0.11 ; p<.001$ ) as well as the curve's shape (significant random slope of the quadratic term: $0.001 ; p<.001$ ) hereby significantly varied inter-individually, indicating that participants differed in their process of habit formation. For $61 \%$ of the participants, the slopes of the quadratic term were negative. Thus, for the majority, increases in habit strength decelerated during the 30 days under investigation. 


\section{[Table 1 about here]}

Four examples illustrate these differences in habit formation. The upper scatterplots in Figure 1 represent the process of habit formation for two specific participants who developed strong habits (habit strength on the last observation day of the two participants: 13), the lower scatterplots represent the process for two specific participants who developed moderate habits (habit strength at the last observation day of the two participants: 7-8). Curve shapes of participants with low habit strength are not depicted as they largely resemble flat lines.

\section{[Figure 1 about here]}

In a second step, we introduced additional variables into the model to answer RQ1 and test hypotheses $\mathrm{H} 2$ and $\mathrm{H} 3$ (Table 2). ${ }^{3}$ The number of omissions led to a decrease in habit strength on the first day following the omission(s) $(b=-0.25 ; t=-2.28 ; p<.05)$. To test whether this was a short-term or lasting effect, we estimated the same model with the number of omissions influencing subsequent days. We found a similarly strong significant effect of the number of omissions on the subsequent day, after the behavior had been performed again $(b=-0.28 ; t=-2.44 ; p<.05)$. Two days after the omission(s) this effect remained negative but became insignificant $(b=-0.18 ; t=-1.42 ; p>.05)$. Three days after the omission(s) the number of omissions did not have a negative effect any more $(b=0.04 ; t=0.33 ; p>.05)$.

\footnotetext{
${ }^{3}$ As the estimation of the models with random slopes for the number of repetitions (linear and quadratic) led to convergence problems, only fixed effects were estimated in the following (Hox, 2010; see 'Limitations' for the potential causes and consequences).
} 
Thus, while omissions lead to a short-term drop in habit strength, this effect petered out within three days (RQ1).

Contrary to $\mathrm{H} 2 \mathrm{a}$, context stability did not affect habit formation: Habits developed irrespective of whether a participant used the app largely during their individually chosen daily occasion or not $(b=0.60 ; t=1.12 ; p>.05)$. Context stability and repetition did not interact $\left(b_{\text {linear }}=0.20 ; t=1.35 ; p>.05 ; b_{\text {quadratic }}=0.00 ; t=-0.71 ; p>.05 ; \mathrm{H} 2 \mathrm{~b}\right.$ not supported).

Supporting H3a, perceived rewards strengthened habit formation $(b=1.74 ; t=3.38$; $p<.001)$. There also was a significant interaction with repetition. Figure 2 illustrates the interaction by means of simple slopes for low $(M-1 S D)$, medium $(M)$, and high $(M+1 S D)$ perceived rewards: Rewarding experiences accelerated habit formation, indicated by the steeper slope $\left(b_{\text {linearXreward }}=0.20 ; t=2.01 ; p<.05 ; \mathrm{H} 3 \mathrm{~b}\right.$ supported $)$. Although not significant $\left(b_{\text {quadraticXreward }}=-0.01 ; t=-1.41 ; p>.05\right)$, less perceived rewards led to a steadier growth of habit strength.

[Table 2 about here]

[Figure 2 about here]

\section{Discussion}

Habit strength is a relevant construct in media research. Knowledge on the formation process of (mobile media application) habits - especially in real-world settings and with human subjects (for laboratory studies see e.g., Verplanken, 2006; for animal studies see e.g., Graybiel \& Smith, 2014) — is surprisingly scarce (exceptions are foremost Armitage, 2005, Lally et al., 2010 as well as studies which do not primarily aim at tracing dynamics in habit formation, e.g., Kim et al. 2005; Murray \& Häubl, 2007; Tokunaga, 2013). Based on a 
longitudinal field study on the formation of a mobile application habits over a period of one month, the present paper investigated the core process of habit formation - the (regular) repetition of a behavior in a specific context which is perceived as rewarding. Centrally, habit strength of selecting the UEFA Euro App 2016 increased with the number of repetitions of the behavior: The more often individuals used the app the less conscious, aware, and controllable they perceived the selection process. Also, as assumed, the relationship between the number of repetitions and habit strength was not linear, but with the number of executions of the mobile media behavior, the increase of habit strength decelerated. The present data emphasize the need to acknowledge this non-linear relationship, which has sometimes been mentioned in habit literature and was previously found by Lally et al. (2010) for healthrelated behaviors, and to withdraw from simplifications of a linear relationship between habit strength and repetition after a habit has formed.

Our results suggest that the influence of repetition on habit formation is largely unaffected by omissions, that is whether or not the behavior was performed regularly. Omissions caused a short-term drop in habit strength. However, this lower level was not sustained, but three days later, the drop was compensated. This confirms the results of Lally et al. (2010) and suggests that whereas repetition of the behavior is of central importance for habit formation, regularity is less important. This, however, may depend on the interval between repetitions. Lally et al.'s (2010), as well as our study, focused on daily behaviors. On the contrary, Armitage's (2005) results indicate an influence of (especially early) omissions for weekly behaviors.

Habit theory suggests that habit strength increases when the behavior is not only repeated, but repeatedly co-occurs with the same contextual features. For example, an individual might use a certain mobile application always at the same time, place, after the same occasion, or in the same mood. The present data does not support this assumption. 
Whether or not an individual had followed their implementation intention reliably, that is had used the app in the same predetermined context every time, did not influence habit formation. The missing interaction effect between number of performance repetitions and context stability suggests that stability of context was neither relevant during the initial phase when the behavior had only been repeated a few times nor during the onward phase after many executions. This may be due to several reasons. For one, the measurement of context stability focused on whether or not participants followed their implementation intention. That is, we presupposed that the occasion which the participants had chosen at the beginning of the study formed the stable context. However, any other internal or external factor may have functioned as a context feature for the respective participant. For example, different from their implementation intention, a participant may have used the app always when boredrepresenting a stable internal context, namely always in the same mood-, always when being worried about a potential threat to their favorite team, or when being reminded of the tournament by other people.

Apart from this potential measurement limitation, the missing relationship between mobile media habit strength and context stability is in accordance with research stating that media habits are not necessarily performed in stable internal or external contexts (Kim, 2014; LaRose, 2010; Naab \& Schnauber, 2016; Newell, 2003; Schnauber, 2017; Schnauber \& Wolf, 2016). Thus, the results at hand indicate the need to rethink the definition of 'context': The concept of habit inherently requires context features to reliably co-occur with the behavior in the process of habit formation. Otherwise, the mental representation of the habitual response cannot form and in consequence the behavior cannot be activated automatically (Wood \& Rünger, 2016). Yet, for media behaviors in general, and specifically the use of a mobile application, the relevant context features might go beyond the features mostly considered. Potentially, the media device use itself in combination with the app icon 
functions as the relevant context: Media content selection proceeds in two stages-first, the user selects a media device, then specific content. Therefore, media device use may be considered a 'gateway behavior' to further-potentially habitual—selection processes (see Oulasvirta, Rattenbury, Ma, \& Raita, 2012 for the idea of 'gateway habits'). The use of the app is imperatively bound to smartphone use as the 'gateway behavior'. The newly adopted app use is chunked into a unit with the already established, and therefore potentially habitualized, smartphone use (see 'Repetition and Regularity'). In particular, after a long history of repetition, which is common for the use of many media devices, the 'gateway behavior' is likely an SR habit, thus a very stable, reward insensitive structure. This already existent structure may provide the relevant context for the adoption of a new-and at first reward sensitive (see below) — AO app habit. In consequence, the use of the media device and the subsequent mere sight of the app icon may serve as context features which always cooccur with the potentially habitual behavior, that is the app use.

The notion of a 'gateway behavior' for habit formation diverges from the concept of context stability as described above. Traditionally, context cues are distinct from the habitual behavior. External and internal context features such as place, time, or mood are commonly regarded as relevant for habit formation and constitute one possible context for the execution of the behavior. For example, the external context feature 'after breakfast' which may serve as a stable context in forming a habit of using the UEFA Euro App 2016 is not mandatory. An individual may use the app after breakfast, but also after lunch, or in any other situation. In contrast, gateway behaviors are inextricably tied to the behavior which is habitualized. A gateway behavior is a stable context that is a necessary precondition for the performance of the habit. App use depends on smartphone use. However, smartphone use is not a sufficient precondition for app use as it is also a gateway to many other behaviors. Nevertheless, the smartphone makes available a range of further cues, specifically the icon of the app as a 
context feature. Recent habit literature has already started to deal with such context features as prerequisites of habit formation (e.g., Carden \& Wood, 2018). For instance, Anderson (2016) reports accumulated experimental evidence from attention research that is applicable to mobile media habits: When a colored shape repeatedly co-occurred with a (rewarded) behavior, participants formed a mental representation of the respective response to the cue. In subsequent trials, individuals habitually focused their attention on the respective colored shape even if it was unrelated to the current task. Applying these findings to mobile media application habits, the mere sight of an app icon on the smartphone screen may serve as a contextual cue and automatically attract attention leading to opening the app. A necessary prerequisite for this automatic selection is the gateway behavior, that is using the smartphone.

In summary, the idea of media device use as gateway behavior and icons as additional cues leads to the notion that stability of traditional external and internal context cues might not be required in the mobile media application habit formation phase. The gateway behavior and the icon might serve as cues, inherent and mandatory, to the repeated execution of the behavior. The concept of gateway behaviors as triggers might be especially relevant to mobile media habits, because mobile media use is predestined to take place in ever changing external circumstances and media use needs some sort of technical device. Yet, habits in other domains might also be automatic responses to gateway behaviors. For example, starting the car might activate the habit of driving to work-even when it is Sunday and one planned to drive to the baker.

The study did not provide a formal test of the role of the gateway behavior and app icon as context features necessary for mobile media application habit formation. However, the relevance of a gateway function of smartphone use is indicated by the result that smartphone habit strength tended to have a positive influence on app habit strength (Table 1 and Table 2). Of course, the results need further confirmation, but they indicate that the 
formation of mobile media application habits does not need performance in stable contexts in a traditional sense to successfully contribute to automatic initiation. This may explain the result that stability of the context features embedded in the implementation intentions did not influence habit formation, since these context cues were traditional features such as places, prior activities, and the like.

The influence of rewards on habit formation has rarely been tested and those tests that have been performed were largely limited to the laboratory (e.g., Anderson, 2016; Murray \& Häubl, 2007) and animal studies (e.g., Graybiel \& Smith, 2014). In line with these former results, habit strength of selecting the UEFA Euro App 2016 increased when the behavior was repeatedly perceived as rewarding. Rewarded users showed a steeper increase in habit strength during the initial phase of just a few repetitions than less rewarded users. However, the influence of perceived rewards petered out over the period of the 30 days under investigation. Thus, rewarding experiences with a media behavior seem to have an impact at the beginning of habit formation but become less relevant later on. This result is in line with the proposed transition from AO to SR habits after intensive execution of a behavior (Smith \& Graybiel, 2016) and LaRose's (2010) differentiation between habit acquisition and habit activation: In early phases of habit formation, habits are reward sensitive (AO). After intensive repetition, reward insensitive SR habits develop. Less satisfied users generally reached a lower level of habit strength, but their progress in habit formation in tendency was more continuous. It may be assumed that after a longer time span, the habit strength curves of more and less rewarded individuals converge.

\section{Limitations}

Several limitations have to be considered when interpreting the results. The preselected media use behavior has consequences for the generalizability of our results. First, participants were not free to choose a behavior they wanted to habitualize. This may limit the 
study's external validity as it is unclear if and for how long individuals are willing to repeat such a behavior under natural circumstances. This may also depend on their motivation to follow their initially formed implementation intention. However, this procedure was appropriate to test the influence of rewards on habit formation in that it created variance in perceived rewards resulting in positive outcome expectations of app use. Furthermore, the results are indicative for intervention strategies where individuals are motivated to habitualize behaviors that may not be gratifying in the short-term. Second, the UEFA Euro App 2016 and its attributes, for example, its content, update intervals, and the complexity of usage, may influence habit formation. By preselecting only one app, the study kept constant many mediaspecific factors that may influence the process of habit formation (see 'A Comprehensive Framework of Media Habit Formation'). This limits generalizability of the results to other media devices and content. Future research should thus systematically vary and test the dynamics of habit formation for different media behaviors including for example different mobile applications with personalized content as well as other media devices. These studies could also include further potentially confounding variables like complementary or substitutionary usage of other related media content (e.g., the use of other information sources on a specific topic like soccer).

The overall habit strength at the end of the field period was relatively low $(\mathrm{M}=3.73$; $S D=4.20$ on a scale from 0 to 16 ). This may lead to the assumption that not much habit formation occurred at all. However, various aspects have to be considered: First, especially the automaticity dimension of habit strength tends to produce low overall levels in different behavioral domains (e.g., Schnauber, 2017 for various media use behaviors, Limayem \& Hirt, 2003 for information systems usage, Gardner \& Tang, 2014 for eating unhealthy snacks and drinking alcohol, and Mittal, 1988 for seatbelt use). This indicates that participants do not necessarily utilize the full scale range for these items, probably due to social desirability- 
individuals do not want to admit they acted automatically—or a limited capability to selfreport on automatic processes (Nisbett \& Wilson, 1977). Second, since participants could not choose an app of their interest, rewards and thus habit strength might be lower than in other studies which examine habitualization of desired behaviors (e.g., Lally et al., 2010). Third, the results are only tentative due to the short duration of the study: The field period of 30 days may have been too short to develop stronger habits (see also Carden \& Wood, 2018). A longer investigation might produce results that are more pronounced. Yet, other authors also support the low overall habit strength with longer periods of investigation (e.g., Limayem \& Hirt, 2003). Fourth, we find inter-individual differences in habit formation. Whereas eight participants (16\%) did not develop habits at all, about the same share (7 participants) showed habit strengths beyond the scale's midpoint at the end of the field period. Thus, our results point to the importance of inter-individual factors in habit formation. Future studies over a longer period might reveal if some people develop habits more slowly but with a similar curve shape or if people generally have different habit formation curves — or do not develop (specific) habits at all.

Related to this, the sample limits the generalizability of the results. First, only undergraduate students participated. However, personal characteristics may influence habit formation: The result that habit formation follows individual patterns (significant random slopes, see Table 1) and that person-level factors play an important role $(\mathrm{ICC}=.66$; Table 1 and 2), but are not accounted for thoroughly in this study further supports that a replication with a heterogeneous sample is needed (see 'A Comprehensive Framework of Media Habit Formation'). Second, the sample size on level 2 (individuals) was rather small $(N=51)$. Whereas this is less problematic for the accuracy of parameter estimations (see 'Data Analysis'), the low number of level-2 units led to convergence problems when estimating random slopes of the number of repetitions to establish individual curve shapes (see 
'Results'). Therefore, only fixed effects models were estimated to account for the influence of additional factors (number of omissions, context stability, and perceived rewards). Thus, the impact of these variables was estimated without accounting for random slope variances. This makes the results tentative as it is possible that the effects found stem from interindividual variance in habit formation better accounted for by random slopes (e.g., Hox, 2010). Future research relying on larger samples will have to put this to an empirical test.

\section{A Comprehensive Framework of Media Habit Formation}

Based on habit theory and the current results, we propose a comprehensive framework of media habit formation. It complements literature modelling habit strength and further determinants of media behavior (see LaRose, 2010, for a model that already distinguishes between determinants during habit formation and habit activation phase, also indicating relationships between outcome expectations, context cues, and habit strength). Figure 3 summarizes the assumed determinants of habit formation.

\section{[Figure 3 about here]}

According to current research, and supported by our results, repetition of behavior execution is undisputedly the central determinant of habit formation. Whether this repetition has to be regular in the sense of uninterrupted without omissions is less clear, as our nullfindings are based on a daily performable behavior (thus, it is in brackets in the model). Whereas many media use behaviors are performed in short intervals, there are numerous examples of less frequent media use behaviors such as turning on Christmas songs or watching the Super Bowl on a yearly basis. Future research will have to systematically evaluate whether the temporal availability of the media content, and in consequence the pattern of repetition, moderates the impact of omissions on media habit formation. 
Repetition alone is not sufficient to form a habit. The formation of a mental representation of the habitual response requires the repeated execution of the behavior to cooccur with context features. Traditionally, one would expect external and internal context features like time, place, mood, and so on to take this role. So far, it has been assumed (LaRose, 2010; Naab \& Schnauber, 2016), but never empirically tested, that media habits also demand stable contexts at least during their formation phase. However, our results indicate that at least mobile media application habits can be formed independently of external circumstances. Presumably, gateway behaviors - in connection with visual cues such as app icons - may constitute the stable context required for the formation of the mental representation of the habitual response instead. Future research will need to look into the role of different context features, including gateway behaviors, more deeply.

The association of context and behavior in memory is strengthened by perceived rewards. We find that repeatedly rewarded behaviors are habitualized faster. Rewards seem to be important for strengthening the formation of the mental representation especially early in the process ('AO habits') but become less relevant later on ('SR habits'). This finding thus indicates that also less rewarding (media) behaviors can be turned into a habit through disciplined repetition. This implies that, for example, interventions trying to establish habits which the individual may not perceive as rewarding need mechanisms that guarantee a long(er) implementation phase of continuous repetitions — whereby few omissions are tolerable. Future research should aim at systematically testing the influence of different reward patterns (e.g., intermittent or continuous rewards) as well as different types of rewards. First results point to differences between direct payoffs of the behavior as tested in our study and monetary or other incentives (Limayem \& Hirt, 2003; Wood \& Neal, 2016).

The core process of habit formation composed of the central elements (regular) repetition, context stability, and perceived rewards is dependent on characteristics of the 
person. Our results show that individuals differ in how easily they adopt habits and in how long the process of habit formation takes (see also Lally et al., 2010): Significant random slopes and the large ICC (.66) support that person-level factors influence habit formation. Whereas the current study did not test potential person-level factors, the model fits leave room for improvement and indicate that such variables are valuable additions to understanding habit formation. Future research should analyze the role of sociodemographics (for a short overview about potential influences of socio-demographics on habitual processing see Venkatesh et al., 2012) and personality characteristics. For example, some individuals have a greater need for structure and therefore embrace repetitive and reliable structures in everyday life and lend to greater habitualization (Thompson et al., 2001) or differ in their trait self-control, leading to differences in their susceptibility to automatic behavioral control (Tangney et al., 2004; Wood \& Rünger, 2016).

Finally, the core process also depends on characteristics of the media use behavior, for example complexity of use, temporal availability, (ubiquitous) access options, and frequency of content updates. Moreover, media behaviors are more or less limited to specific contexts or allow for ubiquitous access. These characteristics set boundary conditions to repetition intervals, regularity, perceived rewards, and the context features relevant for habit formation. Future research should also investigate habit formation for different media platforms and content types to test whether their particularities moderate the habit formation process. Examining further media behaviors may be especially relevant for analyzing contextual features and the supposed importance of gateway behaviors.

In conclusion, the present paper provides an integrative framework on the determinants of habit formation and their interplay which may inspire future research to seek a more complete picture of this highly relevant process. 


\section{Acknowledgments}

We would like to thank Stefan Geiß, the editor, and reviewers for their very helpful comments on earlier versions of the article. Furthermore, we thank the 2016 survey research course at the department of communication (University of Mainz) for their support in conducting the study. 


\section{References}

Anderson, B. A. (2016). The attention habit: how reward learning shapes attentional selection. Annals of the New York Academy of Sciences, 1369(1), 24-39. https://doi.org/10.1111/nyas.12957

Armitage, C. J. (2005). Can the theory of planned behavior predict the maintenance of physical activity? Health Psychology, 24(3), 235-245. https://doi.org/10.1037/02786133.24.3.235

Bargh, J. A. (1994). The four horsemen of automaticity: Awareness, intention, efficiency and control in social cognition. In R. S. Wyer, \& T. K. Scrull (Eds.), Handbook of social cognition, Vol. 1 (pp. 1-40). Hillsdale, NJ: Erlbaum.

Bayer, J. B., \& Campbell, S. W. (2012). Texting while driving on automatic: Considering the frequency-independent side of habit. Computers in Human Behavior, 28(6), 2083-2090. https://doi.org/10.1016/j.chb.2012.06.012

Bayer, J. B., Dal Cin, S., Campbell, S. W., \& Panek, E. (2016). Consciousness and selfregulation in mobile communication. Human Communication Research, 42(1), 71-97. https://doi.org/10.1111/hcre.12067

Carden, L., \& Wood, W. (2018). Habit formation and change. Current Opinion in Behavioral Sciences, 20, 117-122. https://doi.org/10.1016/j.cobeha.2017.12.009

Cohen, J. (1988). Statistical power analysis for the behavioral sciences (2. ed.). Hillsdale, NJ: Erlbaum.

Cooper, R., \& Tang, T. (2009). Predicting audience exposure to television in today's media environment: An empirical integration of active-audience and structural theories. Journal of Broadcasting \& Electronic Media, 53(3), 400-418.

https://doi.org/10.1080/08838150903102204 
Danner, U. N., Aarts, H., \& de Vries, N. K. (2008). Habit vs. intention in the prediction of future behaviour: the role of frequency, context stability and mental accessibility of past behaviour. The British Journal of Social Psychology, 47(Pt 2), 245-265. https://doi.org/10.1348/014466607X230876

Eastman, S. T., \& Ferguson, D. A. (2002). Broadcast/cable/web programming: Strategies and practices. Belmont, CA: Wadsworth/Thomson Learning.

Gardner, B. (2015). A review and analysis of the use of 'habit' in understanding, predicting and influencing health-related behaviour. Health Psychology Review, 9(3), 277-295. https://doi.org/10.1080/17437199.2013.876238

Gardner, B., Abraham, C., Lally, P., \& de Bruijn, G.-J. (2012). Towards parsimony in habit measurement: testing the convergent and predictive validity of an automaticity subscale of the Self-Report Habit Index. The International Journal of Behavioral Nutrition and Physical Activity, 9(102), 1-12. https://doi.org/10.1186/1479-5868-9-102

Gardner, B., de Bruijn, G.-J., \& Lally, P. (2011). A systematic review and meta-analysis of applications of the Self-Report Habit Index to nutrition and physical activity behaviours. Annals of Behavioral Medicine, 42(2), 174-187. https://doi.org/10.1007/s12160-011$9282-0$

Gardner, B., Phillips, L. A., \& Judah, G. (2016). Habitual instigation and habitual execution: Definition, measurement, and effects on behaviour frequency. British Journal of Health Psychology, 21(3), 613-630. https://doi.org/10.1111/bjhp.12189

Gardner, B., \& Tang, V. (2014). Reflecting on non-reflective action: an exploratory thinkaloud study of self-report habit measures. British Journal of Social Psychology, 19(2), 258-273. https://doi.org/10.1111/bjhp.12060

Gollwitzer, P. M. (1999). Implementation intentions: Strong effects of simple plans. American Psychologist, 54(7), 493-503. https://doi.org/10.1037/0003-066X.54.7.493 
Gollwitzer, P. M., \& Sheeran, P. (2006). Implementation intentions and goal achievement: A meta-analysis of effects and processes. Advances in Experimental Social Psychology, 38, 69-119. https://doi.org/10.1016/S0065-2601(06)38002-1

Graybiel, A. M., \& Smith, K. S. (2014). Good habits, bad habits. Scientific American, 310(6), 38-43. https://doi.org/10.1038/scientificamerican0614-38

Holland, R. W., Aarts, H., \& Langendam, D. (2006). Breaking and creating habits on the working floor: A field-experiment on the power of implementation intentions. Journal of Experimental Social Psychology, 42(6), 776-783.

https://doi.org/10.1016/j.jesp.2005.11.006

Hox, J. J. (2010). Multilevel analysis. Techniques and applications (2nd ed.). New York, NY: Routledge.

Hull, C. L. (1943). Principles of behavior: An introduction to behavior theory. New York, NY: Appleton-Century-Crofts.

Ji, M., \& Wood, W. (2007). Purchase and consumption habits: Not necessarily what you intend. Journal of Consumer Psychology, 17(4), 261-276. https://doi.org/10.1016/s10577408(07)70037-2

Kim, B. (2012). The diffusion of mobile data services and applications: Exploring the role of habit and its antecedents. Telecommunications Policy, 36(1), 69-81. https://doi.org/10.1016/j.telpol.2011.11.011

Kim, M. (2014). The effects of external cues on media habit and use: Push notification alerts and mobile application usage habits (dissertation). Michigan State University, MI. Retrieved from https://d.lib.msu.edu/etd/3263/datastream/OBJ/download/The_effects_of_external_cues_o n_media_habit_and_use__push_notification_alerts_and_mobile_application_usage_habit s.pdf 
Kim, S. S., Malhotra, N. K., \& Narasimhan, S. (2005). Two competing perspectives on automatic use: A theoretical and empirical comparison. Information Systems Research, 16(4), 418-432. https://doi.org/10.1287/isre.1050.0070

Klöckner, C. A., Matthies, E., \& Hunecke, M. (2003). Problems of operationalizing habits and integrating habits in normative decision-making models. Journal of Applied Social Psychology, 33(2), 396-417. https://doi.org/10.1111/j.1559-1816.2003.tb01902.x

Lally, P., Chipperfield, A., \& Wardle, J. (2008). Healthy habits: efficacy of simple advice on weight control based on a habit-formation model. International Journal of Obesity, 32(4), 700-707. https://doi.org/10.1038/sj.ijo.0803771

Lally, P., \& Gardner, B. (2013). Promoting habit formation. Health Psychology Review, 7(sup1), 137-158. https://doi.org/10.1080/17437199.2011.603640

Lally, P., van Jaarsveld, C. H. M., Potts, H. W. W., \& Wardle, J. (2010). How are habits formed: Modelling habit formation in the real world. European Journal of Social Psychology, 40(6), 998-1009. https://doi.org/10.1002/ejsp.674

Lally, P., Wardle, J., \& Gardner, B. (2011). Experiences of habit formation: a qualitative study. Psychology, Health \& Medicine, 16(4), 484-489.

https://doi.org/10.1080/13548506.2011.555774

LaRose, R. (2010). The problem of media habits. Communication Theory, 20(2), 194-222. https://doi.org/10.1111/j.1468-2885.2010.01360.x

LaRose, R., \& Eastin, M. S. (2004). A social cognitive theory of Internet uses and gratifications: Toward a new model of media attendance. Journal of Broadcasting \& Electronic Media, 48(3), 358-377. https://doi.org/10.1207/s15506878jobem4803_2 
LaRose, R., Lin, C. A., \& Eastin, M. S. (2003). Unregulated Internet usage: Addiction, habit, or deficient self-regulation? Media Psychology, 5(3), 225-253.

https://doi.org/10.1207/S1532785XMEP0503_01

Limayem, M., \& Hirt, S. G. (2003). Force of habit and information systems usage: Theory and initial validation. Journal of the Association for Information Systems, 4, 65-97.

Limayem, M., Hirt, S. G., \& Cheung, C. M. K. (2007). How habit limits the predictive power of intention: The case of information systems continuance. MIS Quarterly, 31(4), 705-735. https://doi.org/10.2307/25148817

Maas, C. J. M., \& Hox, J. J. (2005). Sufficient sample sizes for multilevel modeling. Methodology, 1(3), 86-92. https://doi.org/10.1027/1614-1881.1.3.86

Mantzari, E., Vogt, F., Shemilt, I., Wei, Y., Higgins, J. P. T., \& Marteau, T. M. (2015). Personal financial incentives for changing habitual health-related behaviors: A systematic review and meta-analysis. Preventive medicine, 75, 75-85.

https://doi.org/10.1016/j.ypmed.2015.03.001

Marcus, B. H., Forsyth, L. H., Stone, E. J., Dubbert, P. M., McKenzie, T. L., Dunn, A. L., \& Blair, S. N. (2000). Physical activity behavior change: Issues in adoption and maintenance. Health Psychology, 19(1S), 32-41. https://doi.org/10.1037//0278-6133.19.suppl1.32

McClelland, J. L., McNaughton, B. L., \& O'Reilly, R. C. (1995). Why there are complementary learning systems in the hippocampus and neocortex: Insights from the successes and failures of connectionist models of learning and memory. Psychological Review, 102(3), 419-457. https://doi.org/10.1037/0033-295X.102.3.419

McDaniel, M. A., \& Einstein, G. O. (1993). The importance of cue familiarity and cue distinctiveness in prospective memory. Memory, 1(1), 23-41. https://doi.org/10.1080/09658219308258223 
McDaniel, M. A., \& Einstein, G. O. (2000). Strategic and automatic processes in prospective memory retrieval: A multiprocess framework. Applied Cognitive Psychology, 14(7), S127S144. https://doi.org/10.1002/acp.775

Mittal, B. (1988). Achieving higher seat belt usage: The role of habit in bridging the attitudebehavior gap. Journal of Applied Social Psychology, 18(12), 993-1016. https://doi.org/10.1111/j.1559-1816.1988.tb01189.x

Murray, K. B., \& Häubl, G. (2007). Explaining cognitive lock-in: The role of skill-based habits of use in consumer choice. Journal of Consumer Research, 34(1), 77-88. https://doi.org/10.1086/513048

Naab, T. K., \& Schnauber, A. (2016). Habitual initiation of media use and a responsefrequency measure for its examination. Media Psychology, 19(1), 126-155. https://doi.org/10.1080/15213269.2014.951055

Newell, J. (2003). The role of habit in the selection of electronic media (unpublished dissertation). Michigan State University, MI.

Nisbett, R. E., \& Wilson, T. D. (1977). Telling more than we can know: Verbal reports on mental processes. Psychological Review, 84(3), 231-259. https://doi.org/10.1037//0033295X.84.3.231

Ouellette, J. A., \& Wood, W. (1998). Habit and intention in everyday life: The multiple processes by which past behavior predicts future behavior. Psychological Bulletin, 124(1), 54-74. https://doi.org/10.1037/0033-2909.124.1.54

Oulasvirta, A., Rattenbury, T., Ma, L., \& Raita, E. (2012). Habits make smartphone use more pervasive. Personal and Ubiquitous Computing, 16(1), 105-114. https://doi.org/10.1007/s00779-011-0412-2 
Peters, O. (2007). Social psychological determinants of mobile communication technology use and adoption (dissertation). University of Twente, Enschede. Retrieved from http://doc.utwente.nl/58107/1/thesis_Peters.pdf

Redish, A. D., Jensen, S., \& Johnson, A. (2008). A unified framework for addiction: vulnerabilities in the decision process. The Behavioral and Brain Sciences, 31(4), 415487. https://doi.org/10.1017/S0140525X0800472X

Scherbaum, C. A., \& Ferreter, J. M. (2009). Estimating statistical power and required sample sizes for organizational research using multilevel modeling. Organizational Research Methods, 12(2), 347-367. https://doi.org/10.1177/1094428107308906

Smith, K. S., \& Graybiel, A. M. (2016). Habit formation. Dialogues in Clinical Neuroscience, 18(1), 33-43.

Schnauber, A. (2017). Medienselektion im Alltag: Die Rolle von Gewohnheiten im Selektionsprozess [Media selection in everyday live: The role of habits in media selection processes]. Wiesbaden: Springer VS.

Schnauber, A., \& Wolf, C. (2016). Media habits and their impact on media channel selection for information use. Studies in Communication | Media (SCM), 5, 105-127. https://doi.org/10.5771/2192-4007-2016-1-105

Snijders, T. A. B. (2005). Power and sample size in multilevel modeling. In B. S. Everitt \& D. C. Howell (Eds.), Encyclopedia of statistics in behavioral science (pp. 1570-1573). Chichester, UK: John Wiley \& Sons, Ltd.

Tangney, J. P., Baumeister, R. F., \& Boone, A. L. (2004). High self-control predicts good adjustment, less pathology, better grades, and interpersonal success. Journal of Personality, 72(2), 271-324. https://doi.org/10.1111/j.0022-3506.2004.00263.x 
Thompson, M. M., Naccarato, M. E., Parker, K. C. H., \& Moskowitz, G. B. (2001). The personal need for structure (PNS) and personal fear of invalidity (PFI) measures: Historical perspectives, current applications, and future directions. In G. B. Moskowitz (Ed.), Cognitive social psychology: The Princeton symposium on the legacy and future of social cognition (pp. 19-39). Mahwah, NJ: Erlbaum.

Tokunaga, R. S. (2013). Engagement with novel virtual environments: The role of perceived novelty and flow in the development of the deficient self-regulation of Internet use and media habits. Human Communication Research, 39(3), 365-393. https://doi.org/10.1111/hcre.12008

Venkatesh, V., Thong, J. Y. L., \& Xu, X. (2012). Consumer acceptance and use of information technology: Extending the unified theory of acceptance and use of technology. MIS Quarterly, 36(1), 157-178.

Verplanken, B. (2006). Beyond frequency: habit as mental construct. The British Journal of Social Psychology, 45(Pt 3), 639-656. https://doi.org/10.1348/014466605X49122

Verplanken, B., \& Aarts, H. (1999). Habit, attitude, and planned behaviour: Is habit an empty construct or an interesting case of goal-directed automaticity? European Review of Social Psychology, 10(1), 101-134. https://doi.org/10.1080/14792779943000035

Verplanken, B., \& Orbell, S. (2003). Reflections on past behavior: A self-report index of habit strength. Journal of Applied Social Psychology, 33(6), 1313-1330. https://doi.org/10.1111/j.1559-1816.2003.tb01951.x

Wood, W., \& Neal, D. T. (2007). A new look at habits and the habit-goal interface. Psychological Review, 114(4), 843-863. https://doi.org/10.1037/0033-295X.114.4.843

Wood, W., \& Neal, D. T. (2016). Healthy through habit: Interventions for initiating \& maintaining health behavior change. Behavioral Science \& Policy, 2(1), 71-83. 
Wood, W., \& Rünger, D. (2016). Psychology of habit. Annual Review of Psychology, 67, 289-314. 


\section{Tables}

Table 1: Multilevel analyses predicting habit strength from the number of repetitions

\begin{tabular}{|c|c|c|c|c|c|c|c|c|}
\hline \multirow[b]{2}{*}{ Fixed effects } & \multicolumn{2}{|c|}{ Model 1} & \multicolumn{2}{|c|}{ Model 2a } & \multicolumn{2}{|c|}{ Model 2b } & \multicolumn{2}{|c|}{ Model 3} \\
\hline & $\mathrm{b}$ & $\mathrm{t}$ & $\mathrm{b}$ & $\mathrm{t}$ & $\mathrm{b}$ & $\mathrm{t}$ & $\mathrm{b}$ & $\mathrm{t}$ \\
\hline \multicolumn{9}{|l|}{ Person level } \\
\hline Constant/intercept & $3.05 * * *$ & 7.00 & $2.09 * * *$ & 4.84 & $1.80 * * *$ & 3.80 & $1.73 * * *$ & 5.19 \\
\hline Smartphone habit strength & - & - & $1.00^{\dagger}$ & 1.80 & $1.00^{\dagger}$ & 1.80 & $0.80^{\dagger}$ & 1.89 \\
\hline \multicolumn{9}{|l|}{ Situation level } \\
\hline Number of repetitions & - & - & $0.08 * * *$ & 9.49 & $0.14 * * *$ & 4.67 & $0.16 * *$ & 2.94 \\
\hline Number of repetitions (quadratic) & - & - & - & - & $-0.01 *$ & -2.09 & $-0.01^{\dagger}$ & -1.84 \\
\hline$\underline{\text { Random effects }}$ & Var & & Var & & var & & var & \\
\hline Constant/intercept & 9.47 & & 8.74 & & 8.74 & & 4.27 & \\
\hline Residual & 4.87 & & 4.51 & & 4.49 & & 3.37 & \\
\hline Number of repetitions & - & & - & & - & & $0.11 * * *$ & \\
\hline Number of repetitions (quadratic) & - & & - & & - & & $0.001 * * *$ & \\
\hline Deviance & 5330.00 & & 5275.40 & & 5235.80 & & 5022.00 & \\
\hline$X^{2}(\mathrm{df})$ & - & & $89.92(2)$ & & $4.35(1)$ & & $213.77(5)$ & \\
\hline $\mathrm{p}$ & - & & $<.001$ & & .037 & & $<.001$ & \\
\hline
\end{tabular}

Note $N_{\text {Person }}=51, N_{\text {Situation }}=1162 ; I C C=.66 ;$ Maddala $R^{2}$ of the final model $=.23 ;$ model 1 : intercept only; model 2: fixed effects (a: linear term only; b: linear and quadratic term); model 3 : fixed \& random effects; unstandardized coefficients; significance test for fixed effects: Wald test; significance test for random slopes: deviance difference test; $* * * p<.001 ; * * p<.01$;

$* p<.05 ;{ }^{\dagger} p<.10$ 
Table 2: Multilevel analyses predicting habit strength from the number of repetitions, omissions, situational stability, and perceived rewards

\begin{tabular}{|c|c|c|c|c|}
\hline \multirow[b]{2}{*}{ Fixed effects } & \multicolumn{2}{|c|}{ Model 1} & \multicolumn{2}{|c|}{ Model 2} \\
\hline & $\mathrm{b}$ & $\mathrm{t}$ & $\mathrm{b}$ & $\mathrm{t}$ \\
\hline \multicolumn{5}{|l|}{ Person level } \\
\hline Constant/intercept & 0.80 & 1.26 & $1.48^{*}$ & 2.12 \\
\hline Smartphone habit strength & $0.94^{\dagger}$ & 1.80 & $0.91^{\dagger}$ & 1.78 \\
\hline \multicolumn{5}{|l|}{ Situation level } \\
\hline Number of repetitions & $0.14 * * *$ & 4.47 & -0.08 & -0.62 \\
\hline Number of repetitions (quadratic) & $-0.01^{\dagger}$ & -1.83 & 0.01 & 0.52 \\
\hline Number of omissions & $-0.25^{*}$ & -2.28 & $-0.24 *$ & -2.16 \\
\hline Situational stability & 0.60 & 1.12 & -0.02 & -0.04 \\
\hline Perceived reward & $1.74 * * *$ & 3.38 & $1.11^{\dagger}$ & 1.88 \\
\hline Number of repetitions $*$ Situational stability & - & - & 0.20 & 1.35 \\
\hline Number of repetitions (quadratic)* Situational stability & - & - & 0.00 & -0.71 \\
\hline Number of repetitions $*$ Perceived reward & - & - & $0.20 *$ & 2.01 \\
\hline Number of repetitions (quadratic)* Perceived reward & - & - & -0.01 & -1.41 \\
\hline Random effects & Var & & var & \\
\hline Constant/intercept & 7.80 & & 7.35 & \\
\hline Residual & 4.45 & & 4.42 & \\
\hline Deviance & 5219.00 & & 5208.80 & \\
\hline$X^{2}(\mathrm{df})$ & $19.93(4)$ & & $10.17(4)$ & \\
\hline $\mathrm{p}$ & $<.001$ & & 0.038 & \\
\hline
\end{tabular}



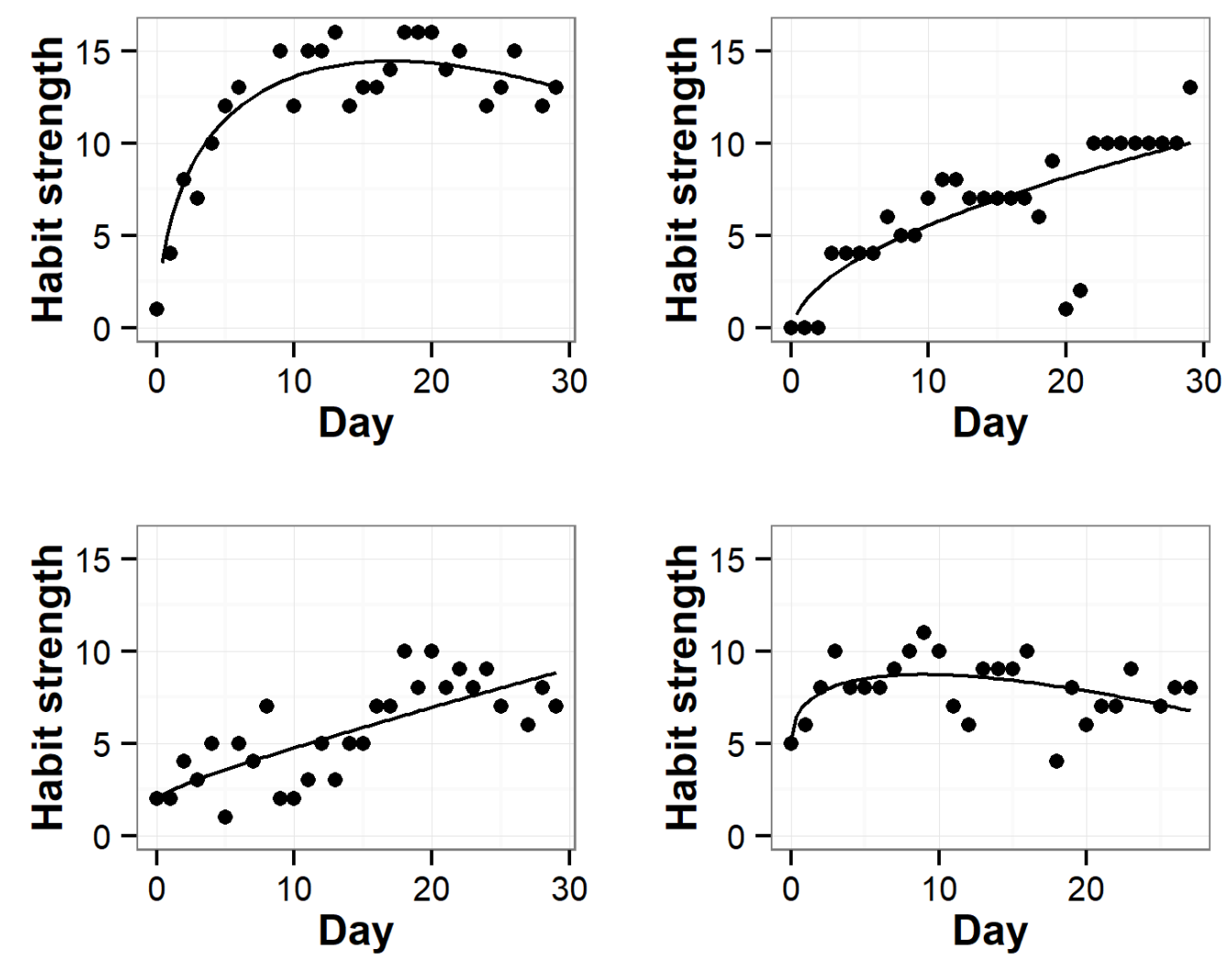

Figure 1. Scatterplots and predicted curve shapes of habit strength of four specific participants over the 30 days of the period under investigation. Upper graphs: Two participants with high final habit strength. Lower graphs: Two participants with moderate final habit strength. 


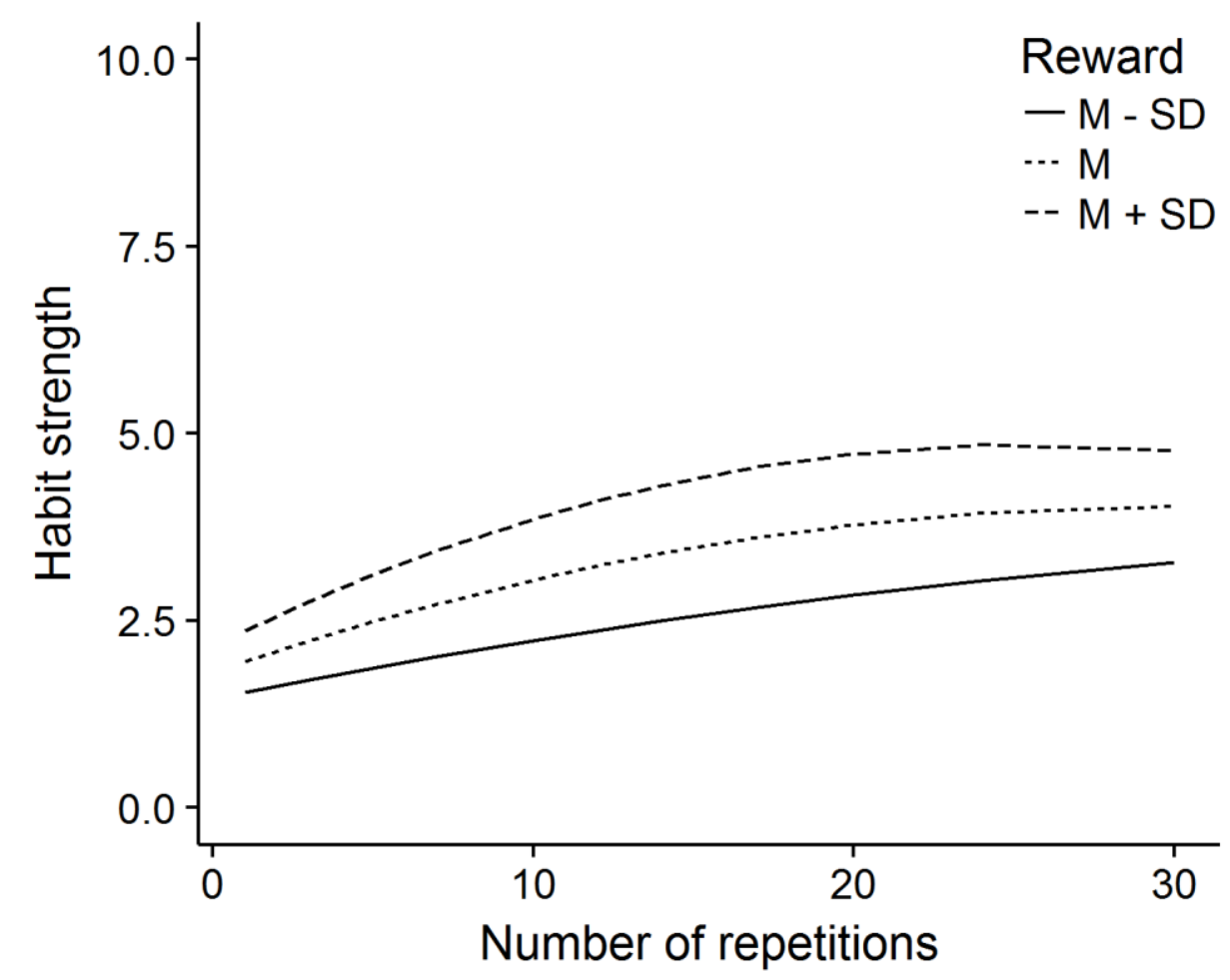

Figure 2. Interaction between the number of repetitions and perceived rewards. 


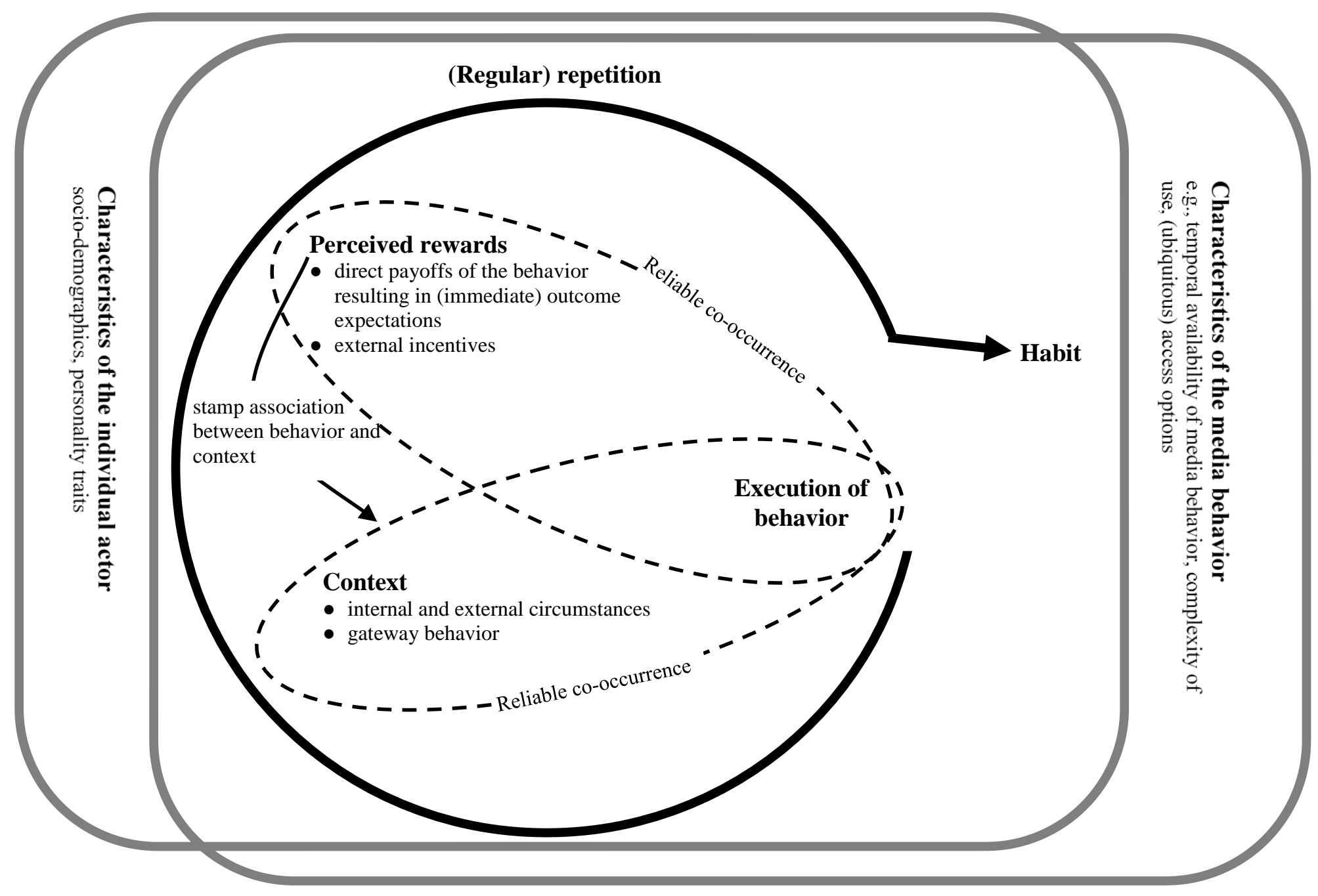

Figure 3. Comprehensive framework of media habit formation. 